\title{
Premunização de plantas afetando a produção de frutos e sementes de abobrinha-de-moita
}

\author{
Antonio Ismael Inácio Cardoso ${ }^{1}$; Marcelo A Pavan \\ ${ }^{1}$ UNESP-FCA, Depto. Prod. Vegetal, C. Postal 237, 18603-970 Botucatu-SP; ismaeldh@fca.unesp.br; mapavan@fca.unesp.br
}

\section{RESUMO}

O objetivo do trabalho foi verificar o efeito protetor de um isolado atenuado de "Papaya ring spot virus - type Watermelon" (PRSV-W) e um de "Zucchini yellow mosaic vírus" (ZYMV) em plantas de abobrinha-de-moita, cultivar Caserta, visando a produção de sementes. Foram testados cinco tratamentos, com seis repetições, no delineamento experimental em blocos ao acaso. Os tratamentos consistiram em: 1) premunização com PRSV-W; 2) premunização com ZYMV; 3) premunização dupla (PRSV-W e ZYMV); 4) testemunha com plantas submetidas à infecção natural; 5) plantas isentas de vírus. Obteve-se maior número de frutos em plantas sem vírus, em comparação aos demais tratamentos, enquanto que a premunização com PRSV-W foi superior à testemunha com infecção natural. No tratamento com premunização dupla foram obtidos frutos com menor massa média que as plantas sem vírus, não havendo diferença entre os outros tratamentos. Para produção de sementes por planta, todos os tratamentos com premunização e a testemunha não diferiram entre si, porém produziram menos que as plantas isentas de vírus. Para a qualidade (germinação e vigor) das sementes não foram verificadas diferenças entre os tratamentos.

Palavras-chave: Cucurbita pepo, PRSV-W, ZYMV, vírus, germinação, vigor.

\begin{abstract}
Premunization affecting fruits and seed production in zucchini squash

The objective of this work was to study the effectiveness of a mild strain of Papaya ring spot virus - type Watermelon (PRSV-W) and a mild strain of Zucchini yellow mosaic virus (ZYMV) in plants of zucchini squash, cv. Caserta, for seed production. Five treatments were tested, with six replications, in randomized block design. The treatments were: 1) premunization with PRSV-W; 2) premunization with ZYMV; 3) double premunization (PRSV-W and ZYMV); 4) control, plants submitted to natural infection; 5) plants without virus infection. Plants without virus produced more fruits, while premunization with PRSV-W was superior to control submitted to natural infection. In treatment with double premunization lighter fruits were obtained, compared to plants without virus, and there were no differences among other treatments. For seed production per plant, all premunization treatments and control with natural infection did not differ from each other, but they produced less than plants without virus. For seed quality (germination and vigor) there were no differences among all treatments.
\end{abstract}

Keywords: Cucurbita pepo, PRSV-W, ZYMV, virus, germination, vigor.

(Recebido para publicação em 25 de outubro de 2011; aceito em 9 de janeiro de 2013)

(Received on October 25, 2011; accepted on January 9, 2013)

\begin{abstract}
A a b o b r in h a - d e - m o i t a (Cucurbita pepo) pertence à família Cucurbitaceae, a mesma da abóbora, chuchu, melancia, melão, moranga e pepino. $\mathrm{O}$ produto comercial é um fruto imaturo, com a polpa muito tenra e as sementes pouco desenvolvidas e macias. As cucurbitáceas, em geral, estão sujeitas a várias doenças causadas por vírus, que podem reduzir substancialmente a sua produtividade. Estudos sobre a incidência destes em cucurbitáceas no estado de São Paulo constataram a presença do "Papaya ring spot virus - type Watermelon" (PRSV-W) em 48,3\% das amostras analisadas, seguido pelo Zucchini yellow mosaic virus (ZYMV) que foi encontrado em 24,5\%
\end{abstract}

das amostras (Yuki et al., 2000). Estes podem causar infecções isoladas e mistas, que são observadas com relativa frequência em condições naturais.

Plantas de abobrinha 'Caserta' inoculadas com PRSV e com ZYMV apresentam sintomas extremamente severos, com mosaico, deformação foliar e bolhosidade (Ramos et al., 2003), sendo maior a redução na produção quanto antes ocorrer a infecção das plantas, podendo chegar a $100 \%$ de perda com infecção em plantas com 10 dias de idade (Yuki et al., 1991).

As medidas de controle geralmente recomendadas para estes virus, especialmente nas espécies nas quais não há cultivares resistentes ou tolerantes, como C. pepo, incluem: eliminação de plantas hospedeiras na vegetação espontânea que ocorrem próximas da área de plantio; programa de controle de afídeos vetores; pulverizações com óleos minerais e uso de substâncias refletoras (Kurozawa et al., 2005). Porém, nem sempre estas medidas são suficientes para evitar grandes perdas de produção, além de algumas serem economicamente inviáveis em certos casos.

A premunização, método de controle no qual as plantas previamente infectadas por uma estirpe atenuada ficam protegidas contra a infecção e/ou manifestação de estirpes mais severas do complexo (Resende, 1996), é uma medida que pode ser utilizada no manejo destas viroses. Em cucurbitáceas, passou a ser considerada uma medida 
importante no controle de viroses a partir dos trabalhos com ZYMV na França. Um variante que induzia sintomas fracos de mosaico nas folhas de melão e abobrinha e nenhum sintoma nos frutos foi selecionado a partir de um isolado obtido por Lecoq et al. (1991).

No Brasil, estudos mostram que a premunização com estirpes atenuadas em abobrinha oferece um controle eficiente, com ganhos significativos na produção de frutos (Rezende, 1996; Cardoso \& Pavan, 2001; Rabelo \& Rezende, 2004; Bonilha et al., 2009). Contudo, os estudos realizados em abobrinha visam controle das viroses na produção de frutos imaturos. Não há relatos sobre a influência desta técnica na produção e qualidade de sementes nesta espécie.

O objetivo deste trabalho foi estudar o efeito protetor de um isolado atenuado de PRSV-W e um de ZYMV em plantas de abobrinha-de-moita, cv. Caserta, na produção e qualidade de sementes.

\section{MATERIAL E MÉTODOS}

O experimento foi instalado na Fazenda Experimental São Manuel, pertencente à Faculdade de Ciências Agronômicas da Universidade Estadual Paulista, em Botucatu, município de São Manuel-SP.

O experimento foi conduzido de março a junho de 2010. Plantas da cultivar Caserta foram utilizadas no presente estudo e a produção de mudas foi feita a partir da semeadura em bandejas de poliestireno expandido de 128 células. Nesta etapa, as bandejas permaneceram em estufa agrícola tipo arco, com pé direito de $2,8 \mathrm{~m}$, largura de $7 \mathrm{~m}$, comprimento de $20 \mathrm{~m}$ e cobertura de polietileno transparente de $150 \mu \mathrm{m}$ de espessura, com tela anti-afídeos nas laterais para impedir entrada de insetos vetores. Aos 14 dias após a semeadura foi feito o transplante das mudas para duas estufas com condições semelhantes à descrita anteriormente, porém com as laterais mantidas abertas possibilitando a entrada de insetos polinizadores e vetores de viroses. A adubação foi de acordo com o recomendado para a cultura por Raij et al. (1996), segundo a análise do solo, sendo aplicados $4 \mathrm{~L}$ de composto orgânico e $200 \mathrm{~g}$ de adubo formulado 4-14-8 por $\mathrm{m}^{2}$ de estufa, e a irrigação foi feita por gotejamento.

Realizaram-se cinco tratamentos: 1) premunização com PRSV-W; 2) premunização com ZYMV; 3) premunização dupla (PRSV-W e ZYMV); 4) testemunha com infecção natural; 5) plantas sem vírus. Foi utilizado o delineamento experimental em blocos ao acaso, com cinco tratamentos e seis repetições, sendo cada parcela constituída por 10 plantas.

Os isolados atenuados de PRSV-W e de ZYMV utilizados foram cedidos pelo Prof. Dr. Jorge AM Rezende (Rezende, 1996; Rabelo \& Rezende, 2004; Bonilha et al., 2009) da ESALQ, Piracicaba-SP e mantidos, isoladamente, em plantas de abobrinha 'Caserta'.

A testemunha foi constituída por plantas não inoculadas, submetidas à infecção natural e o tratamento plantas sem vírus foi constituído por plantas que permaneceram até o final do ciclo sem vírus.

Considerando-se a existência de inóculo natural tanto do PRSV-W como do ZYMV no local, transplantaram-se 20 plantas por parcela no tratamento plantas sem vírus para se poder escolher apenas plantas assintomáticas e sem a presença destes vírus ao final do ciclo, o que foi confirmado com teste ELISA em cada planta assintomática. Desta maneira, foram realizadas colheitas de cada planta individualmente e somente após o resultado do teste misturou-se as sementes das plantas realmente sem vírus para se realizar as avaliações de produção e qualidade das sementes neste tratamento. Como o teste indica a presença do vírus (PRSV-W ou ZYMV), também as plantas que foram naturalmente infectadas por afídeos, com as estirpes atenuadas foram "descartadas" na avaliação de plantas sem vírus.

A técnica de inoculação utilizada foi a mecânica convencional, ou seja, os inóculos correspondentes a cada vírus foram obtidos de folhas de abobrinha infectadas com o isolado atenuado de PRSV-W e/ou ZYMV, macerando-as em almofariz de porcelana, em presença de tampão de fosfato de potássio 0,02 M, pH 7,0, acrescido de sulfito de sódio na mesma molaridade (Matthews, 1981). A inoculação foi feita nas folhas cotiledonares das plantas seis dias após a germinação. As folhas foram polvilhadas com carbureto de silício ("carborundum"), friccionadas com gaze umedecida no extrato e, em seguida, lavadas com água para retirar o excesso de "carborundum" e de inóculo. As mudas permaneceram sob cultivo protegido com tela anti-afídeos após a inoculação por mais quatro dias.

As plantas foram cultivadas no espaçamento $1,0 \times 0,5 \mathrm{~m}$. Os frutos foram colhidos no estádio maduro, caracterizado pela coloração amarelada. Antes da extração das sementes, os frutos permaneceram em repouso por 15 dias para que as sementes pudessem completar o processo de maturação fisiológica (Alvarenga et al., 1991).

Depois da extração, as sementes de cada fruto foram guardadas separadamente em câmara seca (40\% UR e $20^{\circ} \mathrm{C}$ ), para que o teor de água das sementes se estabilizasse em $8,0 \%$. Após este período, com o uso de aparelho separador de sementes por densidade (modelo 'De Leo Tipo 1'), as sementes foram submetidas à limpeza para retirada das chochas e danificadas, classificadas e utilizadas para as avaliações de produção e qualidade.

As seguintes características foram avaliadas: número de frutos maduros por planta; massa média de fruto $(\mathrm{g})$; massa de sementes classificadas por planta $(\mathrm{g})$; massa de sementes classificadas por fruto (g); massa de 100 sementes (g); germinação (\%); primeira contagem do teste padrão de germinação (\%), índice de velocidade de germinação (IVG); emergência em substrato (\%) e número de plantas com sintomas de mosaico.

O teste de germinação foi instalado em novembro de 2010 conforme as Regras de Análises de Sementes (Brasil, 2009), e a primeira contagem das plântulas normais, realizada aos quatro dias, sendo a germinação final aos oito dias. Foram utilizadas 100 sementes por parcela. Cada repetição foi colocada em duas folhas de papel-toalha umedecidas com água destilada em duas vezes sua massa e cobertos com mais uma folha de papel-toalha umedecido, para então serem enrolados e colocados no germi- 
nador, em posição vertical a $25^{\circ} \mathrm{C}$. As avaliações foram diárias e realizadas sempre no mesmo horário até o $8^{\circ}$ dia após a semeadura, para permitir o cálculo do IVG. Este índice é obtido com a somatória do número de sementes germinadas em cada dia dividido pelo número de dias decorridos entre a semeadura e a germinação (Maguire, 1962).

Para avaliação da emergência em substrato, a semeadura (10/12/10) foi realizada em bandejas de poliestireno expandido de 128 células contendo substrato Plantmax ${ }^{\circledR}$ HT. Foram semeadas 100 sementes para cada parcela. As bandejas foram mantidas em casa de vegetação durante as avaliações, com contagem final aos oito dias após a semeadura.

O número de plantas com sintomas de mosaico foi avaliado a partir dos 14 dias após o transplante, sendo realizada semanalmente, por um período de 42 dias, até 18/05/10, num total de sete observações, quando as plantas já estavam entrando em senescência pela maturação dos frutos. Somente as plantas sem quaisquer sintomas foram consideradas assintomáticas. Foram observados mosaico e/ou bolhosidade nas folhas das plantas consideradas sintomáticas. Os resultados foram expressos em porcentagem de plantas com sintomas.

Foram realizadas análises de variância e as médias comparadas pelo teste de Tukey (5\%). Para a característica taxa (\%) de plantas com sintomas de mosaico, foi excluído o tratamento $\mathrm{T} 5=$ plantas sem vírus, sendo analisados apenas quatro tratamentos.

\section{RESULTADOS E DISCUSSÃO}

O aparecimento de plantas com sintomas de mosaico foi constante, porém lento ao longo de todo o período (Figura 1), sendo que a testemunha sempre teve maior taxa em relação aos demais tratamentos. Na avaliação final realizada, a testemunha apresentou a maior taxa de infecção (25\%), não diferindo do tratamento premunizado apenas com ZYMV (20\%), enquanto que com o duplo tratamento observou-se a menor taxa de infecção (9\%) (Tabela 1).

A maior incidência de plantas sin-

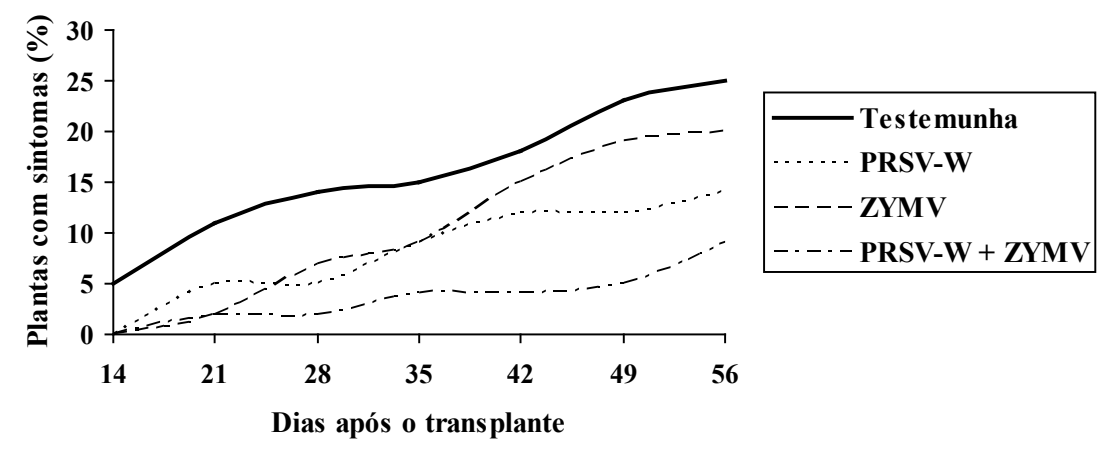

Figura 1. Plantas (\%) com sintomas de mosaico nos diferentes tratamentos (estirpes premunizantes) [plants (\%) with mosaic symptoms in the different treatments (mild strains)]. São Manuel, UNESP, 2010.

tomáticas no tratamento apenas com o ZYMV, em comparação a outros tratamentos com premunização, pode ser explicada pela maior prevalência natural do PRSV-W no estado de São Paulo em relação ao ZYMV (Yuki et al., 2000). Em São Manuel-SP, cerca de $72 \%$ das amostras de plantas de cucurbitáceas com sintomas de mosaico apresentavam infecção por PRSV-W, contra $40 \%$ de ZYMV, já incluídas as infecções mistas. Considerando que a premunização é efetiva apenas para proteger contra a mesma espécie de vírus (Rezende, 1996; Kosaka \& Fukunishi, 1997), plantas tratadas com o ZYMV não estão protegidas contra o PRSV-W, espécie de maior ocorrência.

As plantas sem vírus produziram maior número de frutos por planta $(1,67)$ em comparação a todos os outros tratamentos (Tabela 1). Obteve-se maior valor para essa característica no tratamento com PRSV-W em relação à premunização com ZYMV ou com ambos os vírus. Quanto à testemunha, foi inferior à premunização com PRSV-W para número de frutos, não diferindo do tratamento com ZYMV ou com ambos os vírus.

Para a massa média de frutos, a diferença foi a superioridade das plantas sem vírus em relação à premunização dupla (Tabela 1). Kosaka \& Fukunishi (1997) relataram redução de $15 \%$ na produção de frutos em pepino pela inoculação com três isolados atenuados de diferentes vírus (CMV, ZYMV e WMV-2) quando comparado às plantas sadias, mostrando que a inoculação com mais de um vírus atenuado pode prejudicar as plantas.
Esses autores também recomendam que somente seja feita a premunização múltipla se houver a presença de todos os vírus utilizados; caso contrário, pode haver redução na produção de frutos, recomendando o tratamento apenas com as espécies presentes na área, o que foi feito na presente pesquisa, onde foram testados isolados atenuados das duas espécies de maior ocorrência no estado de São Paulo.

Pacheco et al. (2003) verificaram que os valores de biomassa das plantas de abobrinha infectadas pelas estirpes atenuadas de PRSV-W sofreram reduções que variaram de 1,7 a 12,4\%, quando comparadas às das plantas sadias. Quando infectadas com a estirpe severa, as reduções de biomassa variaram de 29 a 74\%. Bonilha et al. (2009), trabalhando com produção de frutos imaturos de quatro híbridos de abobrinha, observaram que a infecção com o isolado atenuado de PRSV-W só ou em mistura com o de ZYMV pode provocar sintomas em frutos e reduzir a produção por planta em comparação à planta sadia. No entanto, na presente pesquisa, o isolado atenuado de PRSV-W isoladamente não foi mais prejudicial que o de ZYMV ou a mistura. Pelo contrário, resultou em maior produção de frutos por planta, diferindo de Bonilha et al. (2009). Considerando-se que os isolados utilizados por Bonilha et al. (2009) são os mesmos utilizados nesta pesquisa, observa-se que os resultados podem variar de acordo com a cultivar, as condições ambientais e o estádio de colheita dos frutos.

Quanto à produção de sementes por 
Tabela 1. Plantas com sintomas de mosaico (PSM), número de frutos (NrFr) por planta, massa média de fruto (MMF) e produção de sementes por planta (PSP) e por fruto (PSF) nos diferentes tratamentos [plants with mosaic symptoms (PSM), number of fruits (NrFr) per plant, average fruit weight (MMF) and seed production per plant (PSP) and per fruit (PSF) in the different treatments]. São Manuel, UNESP, 2010.

\begin{tabular}{lccccc}
\hline Tratamento & PSM (\%) & NrFr & MMF (g/fruto) & PSP (g/planta) & PSF (g/fruto) \\
\hline Premunização com PRSV-W & $14 \mathrm{bc}$ & $1,44 \mathrm{~b}$ & $1102 \mathrm{ab}$ & $23,1 \mathrm{~b}$ & $19,8 \mathrm{ab}$ \\
Premunização com ZYMV & $20 \mathrm{ab}$ & $1,26 \mathrm{c}$ & $1045 \mathrm{ab}$ & $19,3 \mathrm{~b}$ & $14,3 \mathrm{~b}$ \\
Premunização: PRSV-W + ZYMV & $9 \mathrm{c}$ & $1,24 \mathrm{c}$ & $968 \mathrm{~b}$ & $19,4 \mathrm{~b}$ & $15,7 \mathrm{~b}$ \\
Testemunha & $25 \mathrm{a}$ & $1,23 \mathrm{c}$ & $1027 \mathrm{ab}$ & $20,1 \mathrm{~b}$ & $16,9 \mathrm{ab}$ \\
Plantas sem vírus & $--*$ & $1,67 \mathrm{a}$ & $1284 \mathrm{a}$ & $35,7 \mathrm{a}$ & $24,0 \mathrm{a}$ \\
\hline CV (\%) & 17,0 & 2,4 & 12,3 & 15,8 & 23,3 \\
\hline
\end{tabular}

Médias seguidas pela mesma letra, nas colunas, não diferem pelo teste de Tukey (5\%) (means followed by the same letter, at columns, did not differ from each other by Tukey test at $5 \%$ of probability); *No tratamento plantas sem vírus não foi avaliada a porcentagem de plantas com sintomas de mosaico (in treatment plants without virus, the percentage of plants with mosaic symptoms was not evaluated).

planta, obteve-se menor produção em plantas premunizadas e na testemunha com infecção natural que no tratamento com plantas sem vírus (Tabela 1). Plantas premunizadas com ZYMV ou com PRSV-W + ZYMV resultaram em menor produção de sementes por fruto em comparação com o tratamento plantas sem vírus. Bonilha et al. (2009) relataram que, quando houve diferença na produção de frutos, o isolado atenuado de PRSV-W foi mais prejudicial que o de ZYMV, levando à formação de alguns frutos com sintomas de mosaico. Porém, frutos com leves sintomas de mosaico também produzem sementes e devem translocar nutrientes para as mesmas possibilitando a formação de sementes viáveis. Além disto, a incidência de plantas com sintomas de mosaico nas parcelas onde as mesmas foram premunizadas apenas com o ZYMV foi maior (Figura 1) pela menor ocorrência natural deste vírus na área experimental em relação ao PRSV-W, acarretando maior perda na produção de sementes.

Duas hipóteses podem explicar o fato da testemunha não ter diferido dos tratamentos com premunização: 1) a baixa e tardia infecção natural das plantas da testemunha (Figuras 1); e 2) o ciclo curto e o baixo número de frutos maduros que normalmente uma planta de abobrinha consegue fixar. Normalmente os danos causados por estes vírus às plantas são maiores quanto mais cedo as plantas são infectadas (Yuki et al., 1991), podendo chegar a $100 \%$ quando inoculadas até os dez dias de idade. Trabalhando com ZYMV, Fletcher et al. (2000) relataram redução na massa média de frutos maduros em Cucurbita maxima de 71 e 56\% quando as plantas foram inoculadas logo após o plantio e próximo ao florescimento, respectivamente. Quando a inoculação foi realizada próximo da colheita, não houve redução. Resultados semelhantes foram observados por Pereira et al. (2007) em abobrinha. Em melancia, infecções naturais baixas dificultam a obtenção de resultados mais satisfatórios em pesquisa com premunização (Dias \& Rezende, 2001).

Sobre o ciclo curto, ao contrário da colheita no estádio imaturo, com a qual se pode obter mais de 20 frutos por planta (Tokunaga \& Cardoso, 2001), quando os frutos são deixados na planta até amadurecerem é normal obter-se apenas 1 ou 2 frutos por planta e, não raro, até plantas sem frutos maduros ao final do ciclo (Lima et al., 2003). Rech et al. (2006) observaram, em abobrinha ' $\mathrm{Ca}$ serta', que somente uma em cada quatro ou cinco flores femininas resultava em fruto maduro ao final do ciclo. Segundo Stephenson et al. (1988), quando não se realiza a colheita no estádio imaturo, os frutos competem entre si por assimilados e ocorre o abortamento de flores femininas e da maioria dos frutos, permanecendo geralmente os mais velhos ou com mais sementes. Considerando-se que a fixação dos frutos para produção de sementes ocorre, geralmente, logo após a antese das primeiras flores femininas (cerca de 40 a 50 dias após a semeadura), a infecção natural, neste estádio, ainda era baixa para afetar a fixação de frutos na maioria das plantas. Ressalta-se ainda que as mudas da tes- temunha também foram produzidas em viveiro com tela anti afídeos, ou seja, foram ao campo sadias pelo menos até os 14 dias após a semeadura. Apesar disto, a premunização apenas com a estirpe de PRSV-W, espécie predominante, favoreceu aumento no número de frutos por planta em relação à testemunha com infecção natural, mas não foi o suficiente para aumentar a produção de sementes.

Não foram observadas diferenças entre todos os tratamentos para a massa de 100 sementes, com média de $12,7 \mathrm{~g}$ $(\mathrm{CV}=6,5 \%)$. Esta é uma característica genética da cultivar e o fato dos frutos terem ficado em repouso antes da extração, favorecendo a uniformização da maturação das mesmas (Alvarenga et al., 1991), e a avaliação ter sido realizada com sementes classificadas, explicam a ausência de diferença. Os valores obtidos são semelhantes aos relatados por Lima et al. (2003) e por Rech et al. (2006), com a mesma cultivar.

Quanto à qualidade fisiológica das sementes, não houve diferença entre os tratamentos para todas as características avaliadas. Pode-se dizer que as sementes de todos os tratamentos apresentam boa qualidade, com germinação média de $89 \%(\mathrm{CV}=10,9 \%)$ e emergência em bandeja média de 98\% $(\mathrm{CV}=6,1 \%)$. Estes testes foram realizados em dezembro de 2010, sendo o de germinação sob temperatura controlada $\left(25^{\circ} \mathrm{C}\right)$ e o de emergência realizado em estufa agrícola onde as temperaturas médias diárias foram sempre superiores a $25^{\circ} \mathrm{C}$. Em abobrinha, temperaturas entre $25 \mathrm{e}$ $35^{\circ} \mathrm{C}$ favorecem a germinação (George, 1999) e, provavelmente, este fator favo- 
receu a obtenção de maiores valores para emergência em relação à germinação aos oito dias, sendo que algumas parcelas chegaram a $100 \%$ de emergência. Quanto à primeira contagem, os valores também foram elevados, com média de $83 \%(\mathrm{CV}=13,9 \%)$. Quanto ao IVG, os valores médios obtidos foram de 18,8 $(\mathrm{CV}=5,6 \%)$. Germinação e emergência rápidas são vantajosas por permitirem a obtenção de mudas em menor tempo, reduzindo o custo no viveiro.

Todos os valores de germinação além de serem superiores ao mínimo exigido pela legislação brasileira, também foram superiores ao relatado por Nerson (2005), média de 61\% em abobrinha tipo 'Zucchini' e por Salata et al. (2008), valores de 50 a $83 \%$, e semelhante ao obtido por Lima et al. (2003), de 91 a 98\% em abobrinha 'Caserta', por Cardoso (2005), de 88 a $96 \%$ e por Ghanbari et al. (2007), de 89 a 96\%, confirmando que a premunização não afeta a qualidade das sementes.

Nesta pesquisa observou-se que a premunização foi eficiente em reduzir a taxa de plantas com sintomas de mosaico. Porém, apenas para o número de frutos por planta a premunização, com PRSV-W, foi superior à testemunha com infecção natural, não havendo diferença estatística para as outras características. Em comparação às plantas sem vírus, a premunização, principalmente com ZYMV, reduziu a produção de frutos e de sementes por planta, sem, no entanto, afetar a qualidade fisiológica das mesmas.

\section{AGRADECIMENTOS}

Os autores agradecem à Fundação de Amparo à Pesquisa do estado de São Paulo (Fapesp) pelo auxílio financeiro ao projeto, ao Conselho Nacional de Desenvolvimento Científico e Tecnológico (CNPq) pelas bolsas de Produtividade em Pesquisa e ao Prof. Dr. Jorge Alberto Rezende pela cessão das estirpes

atenuadas.

\section{REFERÊNCIAS}

ALVARENGA EM; SILVA RF; ARAÚJO EF; LEIRO LS. 1991. Maturação fisiológica de sementes de abóbora italiana. Revista Brasileira de Sementes 13: 147-150.

BONILHA E; GIORIA R; KOBORI RF; DELLA VECCHIA PT; PIEDADE SMS; REZENDE JAM. 2009. Yield of varieties of Cucurbita pepo preimmunized with mild strains of PRSV-W and ZYMV. Scientia Agricola 66: 419-424.

BRASIL. Ministério da Agricultura e Reforma Agrária. 2009. Regras para análise de sementes. Brasília: Secretaria Nacional de Defesa Agropecuária/Coordenação de laboratório vegetal. $365 \mathrm{p}$.

CARDOSO AII. 2005. Polinização manual em abobrinha: efeitos na produção de frutos e de sementes. Horticultura Brasileira 23: 731-734.

CARDOSO AII; PAVAN MA. 2001. Premunização de abobrinha-de-moita para o controle do mosaico pelo vírus do mosaico do mamoeiroestirpe melancia. Biotemas 14: 23-26.

DIAS PRP; REZENDE JAM. 2001. Problemas na premunização de melancia para o controle do mosaico causado pelo PRSV-W. Fitopatologia Brasileira 26: 651-654.

FLETCHER JD; WALLACE AR; ROGERS BT. 2000. Potyviruses in New Zealand buttercup squash: yield and quality effects of ZYMV and WMV-2 virus infections. New Zealand Journal of Crop and Horticultural Science 28: 17-26.

GEORGE RT. 1999. Vegetable seed production. New York: CABI Publishing. 328p.

GHANBARI A; NADJAFI F; SHABAHAN J. 2007. Effects of irrigation regimes and row arrangement on yield, yield components and seed quality of pumpkin (Cucurbita pepo L.). Asian Journal of Plant Sciences 6: 1072-1079.

KOSAKA Y; FUKUNISHI T. 1997. Multiple inoculation with three attenuated viruses for the control of cucumber virus disease. Plant Disease 81: 733-738.

KUROSAWA C; PAVAN MA; REZENDE JAM. 2005. Doenças das cucurbitáceas. In: KIMATI H. et al. Manual de fitopatologia: doenças das plantas cultivadas. Piracicaba: ESALQ. p.293-302.

LECOQ H; LEMAIRE JM; WIPF-SCHEIBEL C. 1991. Control of zucchini yellow mosaic virus in squash by cross protection. Plant Disease 75: 208-211.

LIMA MS; CARDOSO AII; VERDIAL MF. 2003. Plant spacing and pollen quantity on yield and quality of squash seeds. Horticultura Brasileira 21: 443-447.

MATTHEWS REF. 1981. Plant virology. New
York: Academic Press. 897p.

MAGUIRE JD. 1962. Speed of germination aid in selection and evaluation for seedling emergence and vigor. Crop Science 2: 176-177.

NERSON H. 2005. Effects of fruit shape and plant density on seed yield and quality of squash. Scientia Horticulturae 105: 293-304.

PACHECO DA; REZENDE JAM; PIEDADE SMS. 2003. Biomass, virus concentration and symptomatology of cucurbits infected by mild and severe strains of Papaya ringspot virus. Scientia Agricola 60: 691-698.

PEREIRA MJC; SUSSEL AAB; SILVA RF; KUHN OJ; DOMINGUES F; REZENDE JAM. 2007. Danos na produção da abobrinhade-moita causados pelo PRSV-W e ZYMV. Summa Phytopathologica 33: 192-194.

RABELO LC; REZENDE JAM. 2004. Seleção de uma estirpe fraca do ZYMV com potencial para uso na premunização. Summa Phytopathologica 30: 340-345.

RAIJ B; CANTARELLA H; QUAGGIO JA; FURLANI AMC. 1996. Recomendações de adubação e calagem para o Estado de São Paulo. 2.ed. Campinas: Instituto Agronômico \& Fundação IAC. 285p.

RAMOS NF; LIMA JAA; GONÇALVES MFB. 2003. Efeitos da interação de potyvirus em híbridos de meloeiro, variedades de melancia e abobrinha. Fitopatologia Brasileira 28: 199-203.

RECH EG; FRANKE LB; BARROS IBI. 2006. Adubação orgânica e mineral na produção de sementes de abobrinha. Revista Brasileira de Sementes 28: 110-116.

REZENDE JAM. 1996. Premunização de duas espécies e um híbrido de Cucurbita para o controle do mosaico causado pelo vírus do mosaico do mamoeiro - estirpe melancia. Piracicaba: USP-ESALQ. 88p. (Tese livre docência).

SALATA AC; BERTOLINNI EV; CARDOSO AII. 2008. Armazenamento de botões florais para produção de sementes de abóbora com polinização manual. Bragantia 67: 587-591.

STEPHENSON AG; DEVLIN B; HORTON JB. 1988. The effects of seed number and prior fruit dominance on the pattern of fruit production in Cucurbita pepo (zucchini squash). Annals of Botany 62: 653-661.

TOKUNAGA JH; CARDOSO AII. 2001. Avaliação de cultivares de abobrinha-demoita. Biotemas 14: 37-46.

YUKI VA; COSTA AS; NAGAI V. 1991. Avaliação de perdas induzidas pelo mosaico da abobrinha-de-moita, causado pelo vírus do mosaico do mamoeiro - estirpe melancia (VMM-Me). Summa Phytopathologica 17: 40.

YUKI VA; REZENDE JAM; KITAJIMA EW; BARROSO PAV; KUNIYUKI H; GROPPO GA; PAVAN MA. 2000. Occurrence, distribution and relative incidence of five viruses infecting cucurbits in the State of São Paulo. Plant Disease 84: 516-520. 